\title{
Elective laparoscopic diverticular resection
}

\author{
A. Chandra $\cdot$ A. Hussain $\cdot$ B. Aravind $\cdot$ \\ H. Almusawy $\cdot$ J. Saunders
}

Published online: 5 March 2009

(C) Springer Science+Business Media, LLC 2009

Dear Editors,

We read with interest the article of Garrett et al. [1] which has been published in the Surg. Endosc. We complement the authors on an impressive case series that addresses the issues of elective laparoscopic resection in diverticular disease. However, we think their report would benefit from a few minor clarifications.

By including every patient over a given period from their unit, they have attempted to provide an honest and thorough overview of their experience, although it is retrospective. With regard to the suitability of patients for the operation, were any criteria used in selecting patients or any patients excluded? One suspects an inevitable selection by the operating surgeon. Although we appreciate that other studies have used the Hinchey criteria, are these criteria appropriate considering they initially were described for acute diverticulitis?

We were impressed to see that patients with complicated diverticular disease (e.g., fistulae and abscesses) also were included but wondered whether they experienced any difference in their outcome. The conversion rate was unclear because the report stated that $6 \%$ underwent conversion to open procedure but also quoted $16 / 200(8 \%)$ in the discussion. Additionally, another four patients $(2 \%)$ underwent conversion to a hand-assisted technique. This rate still is lower than the $26 \%$ quoted by Vargas et al. [2], although not as low the rate cited by Reissfelder et al. [3]. In terms of Table 4, the papers by

A. Chandra · A. Hussain $(\bowtie) \cdot$ B. Aravind · H. Almusawy · J. Saunders

Department of General Surgery, Princess Royal University

Hospital, London, Kent, UK

e-mail: azahrahussain@yahoo.com both Vargas et al. [2] and Reissfelder et al. [3] described the technique as laparoscopically assisted. Do the authors believe their technique differs from the procedure described in these papers they have chosen to use for their comparisons?

The authors stated that the conversion rate is not related to the surgeon's experience. However, the outcome of a surgical procedure is related to the surgeon's experience in dealing with the anatomy and pathology presented to him or her, and this is clearly highlighted in the literature. Most eminent surgeons anecdotally state that they are still learning and still improving. As a point of interest, do the authors think any benefit is to be gained by continuing on with a nearly 6-hour procedure instead of opting for conversion? Was there any specific reason for this considering it appears to be a marked deviation from the remainder of the procedures?

Overall, this paper should encourage surgeons to apply minimal access surgery to the management of the common disease described.

\section{References}

1. Garrett KA, Champagne BJ, Valerian BT, Peterson D, Lee EC (2008) Asingle training center's experience with 200 consecutive cases of diverticulitis: can all patients be approached laparoscopically? Surg Endosc 22: 2503-2508

2. Vargas HD, Ramirez RT, Hoffman GC, Hubbard GW, Gould RJ, Wohlgemuth SD et al (2000) Defining the role of laparoscopicassisted sigmoid colectomy for diverticulitis. Dis Colon Rectum 43:1726-1731

3. Reissfelder C, Buhr HJ, Ritz JP (2006) Can laparoscopically assisted sigmoid resection provide uncomplicated management even in cases of complicated diverticulitis? Surg Endosc 20:10551059 